\title{
How Currency Denomination and the ATM Affect the Way We Pay
}

\section{Oz Shy}

\section{Working Paper 2019-2b \\ February 2019 (revised March 2020)}

\begin{abstract}
I show how currency denomination and the ATM influence consumers' choice of whether to pay cash for in-person purchases. I identify transaction values above which consumers switch from paying cash to paying with cards. The sharpest changes in the share of cash payments occur at $\$ 20$ and $\$ 40$, which coincide with the observation that most ATMs in the United States dispense multiples of $\$ 20$ bills. Other thresholds prevail at multiples of $\$ 5$ and $\$ 10$. The above thresholds generate asymmetries in consumer behavior where the share of cash payments increases for payments values just below the thresholds and decreases just above them.
\end{abstract}

JEL classification: D9, E42

Key words: currency denomination, automated teller machines, ATM, cash payments, consumer payment choice, payment methods, in-person purchases

https://doi.org/10.29338/wp2019-02b

The author thanks seminar participants at the Federal Reserve of Atlanta for most valuable comments on earlier drafts. The views expressed here are those of the author and not necessarily those of the Federal Reserve Bank of Atlanta or the Federal Reserve System. Any remaining errors are the author's responsibility.

Please address questions regarding content to Oz Shy, Research Department, Federal Reserve Bank of Atlanta, 1000 Peachtree St. NE, Atlanta, GA 30309-4470, oz.shy@atl.frb.org.

Federal Reserve Bank of Atlanta working papers, including revised versions, are available on the Atlanta Fed's website at www.frbatlanta.org. Click "Publications" and then "Working Papers." To receive e-mail notifications about new papers, use frbatlanta.org/forms/subscribe. 


\section{Introduction}

Data collected on how consumers pay in the United States reveal two important characteristics of cash payments for in-person purchases: First, the use of cash declines with the payment value (dollar amount), see for example Kumar and O'Brien (2019). Second, a large number of consumers switch from paying cash to paying with cards for payment amounts exceeding the \$20 and $\$ 40$ thresholds (and to a lesser degree, for payment amounts exceeding multiples of $\$ 5$ and $\$ 10$ thresholds). The second observation provides the motivation for this paper given the observation that automated teller machines (ATMs) in the United States dispense mostly multiples of \$20 bills (although a growing number of ATMs now also dispense $\$ 5$ and $\$ 10$ bills). Because currency notes are denominated in fixed amounts, paying with cash subjects buyers to what is known as the "burden of receiving and carrying change." The burden of change is larger for transaction values farther away from multiples of $\$ 5, \$ 10$, and $\$ 20$ where buyers must exchange bills with fixed denominations for smaller denomination currency notes and coins. The above thresholds generate asymmetries in consumer behavior where the share of cash payments increases for payments values just below the thresholds and decreases just above them.

This article utilizes various statistical techniques to conduct empirical analyses of consumers who choose between paying cash and paying with cards for in-person purchases. The analysis in this paper focuses on buyers' choice among paying with cash, check, credit, debit, and prepaid cards, and how this choice is affected by the available currency denomination.

There are three main reasons why this investigation is important: Firstly, it provides a reason for maintaining a variety of currency denominations in the forms of currency bills, and making them available through ATMs that are capable of dispensing multiple denominations (as opposed to ATMs that dispense only $\$ 20$ bills). Secondly, this research highlights the importance of proper determination of optimal currency denomination. The literature on the latter is discussed in Section 6. Thirdly, there are instances in which currency and coin denominations influence how merchants set prices. This literature is discussed below in this introduction.

From consumers' perspective, cash has some unique characteristics that make cash different from other payment methods such as checks, debit cards, credit cards, prepaid cards, and bank 
account transfers: (i) Cash is circulated for free, although some consumers may encounter fees for ATM withdrawals. (ii) Cash is transferable in both directions among consumers and retailers. (iii) Use of cash results in an immediate and final settlement since there is no need for clearing via banks. Therefore, paying cash makes it easier to control spending. (iv) Cash transactions preserve the anonymity and privacy of the transacting parties because they are not recorded on any server. (v) Cash is still a widely acceptable form of payment (legal tender) although it is limited to inperson transactions. That is, both parties to each cash transaction must be present. ${ }^{1}$

There are some drawbacks of using cash: (a) Cash can be stolen or lost. (b) Cash does not have any record-keeping capability in which consumers can trace back their payments. This feature is a direct consequence of the anonymity property. For that reason, some consumers may actually dislike anonymity because they want to keep a traceable record for every transaction.

The complexity of analyzing the burden of receiving and handling change stems from the fact that change is composed of currency notes and metal coins. Knotek $(2008,2011)$ call it the "relative inconvenience of price" where inconvenience is measured by the minimum number of coins and bills needed to make a transaction. Therefore, currency denomination also affects how prices are set because some merchants take into consideration the burden on consumers from receiving change in cash. Consequently, merchants may adjust their prices to minimize the amount of time spent on handing and sorting change. Examples include printed newspapers that are generally priced at multiples of quarter coins in order to avoid handling pennies. Levy and Young (2004) argue that consumer convenience is also part of the explanation why a bottle of Coca Cola was priced at $5 \varnothing$ (a nickel) for almost 70 years (1886 to 1959).

The empirical findings in this paper are somewhat similar to results obtained in Bouhdaoui, Bounie, and François (2014). Using diary data from France, they identify higher frequency of cash use at transaction values that minimize the number of monetary units (tokens) that are needed to be exchanged. The authors explain these findings by the "principle of least effort" in which transaction amounts $10 €, 20 €, 30 €$, and $50 €$ are considered to be convenient prices. At these

\footnotetext{
${ }^{1}$ There are exceptions. Vending machines and self-checkout counters may require only the presence of the buyer and a virtual seller. In practice, however, many self-checkout counters in the US still require a service person to stand nearby to help buyers who face difficulties in getting through self-checkout counters.
} 
prices buyers and sellers have higher motivation to use cash.

In contrast, using US diary data, I identify the peaks of cash use at transaction values that correspond to multiplies of $\$ 20$ (and to a lesser degree to multiples of $\$ 10$ and $\$ 5$ ). These peaks correspond to ATMs and currency denomination in the US. I also identify an asymmetric consumer behavior where the share of cash payments sharply increases for payment values just below the thresholds and sharply decreases for payment values just above these thresholds.

In general, cash use at the point-of-sale (POS) remains strong in most countries. Krüger and Seitz (2014), Fung, Huynh, and Stuber (2015), Arango, Huynh, and Sabetti (2015), Bounie, François, and Waelbroeck (2016), Wang and Wolman (2016), Wakamori and Welte (2017), Chen, Huynh, and Shy $(2019)$, and Shy $(2018,2019)$ explore the intensity of cash use, and how cash dominates low value transactions. Studies by Bagnall et al. (2016), Bech et al. (2018), and Khiaonarong and Humphrey (2019) provide international comparisons of the intensity of cash use.

This article is organized as follows. Section 2 sketches a single-currency denomination model of consumer preferences that provides some intuition for the empirical findings on how the decision to pay cash is influenced by currency denomination. Section 3 describes the data and defines the variables of interest. Section 4 analyzes ATM cash withdrawals. Section 5 presents the main empirical results identifying payment amount thresholds that determine consumer payment choice. Section 6 concludes.

\section{A simple model of consumer preferences for paying cash}

This section briefly sketches the analytics of consumer preferences for paying cash. Although these preferences are restricted to a single-currency denomination, they provide some intuition for the empirical findings on the use of cash described in this paper.

Consider a consumer who faces a decision whether to pay cash (C) or with a non-cash payment instrument (NC) for an in-person purchase made at a retailer who accepts both cash and non-cash (card) payments. Assume that the consumer carries multiples of the same currency note, each denominated by $\$ m(m>0)$. For example, the consumer may carry 5 bills denominated by $\$ 20$. The consumer enters a store, selects the items and finds out the total tax-inclusive payment 
amount $p$. I assume that the consumer carries a sufficient number of (same currency) bills to be able to pay the amount $p$. Any payment amount $p$ must fall in one price range

$$
(k-1) m<p \leq k m \quad \text { for one value of } k \in\{1,2, \ldots\}
$$

A payment value not exceeding the currency denomination $m$ is captured by $k=1$, in which case $p \in(0, m]$. This range includes low-value payments (such as $50 \varnothing$ ) and higher values (close to $m) . k=2$ implies that the payment amount lies in the range $p \in(m, 2 m]$. For a given currency denomination $m$, after the consumer finds out the payment amount $p$, the consumer can also figure out the value of the integer $k$ which determines the payment amount range that $p$ belongs to so that $p \in((k-1) m, k m]$.

For a given currency denomination $m$, after observing the payment value $p$ and hence $k$, the consumer decides on whether to pay cash (C) or with a non-cash payment instrument (NC) to maximize the utility function ${ }^{2}$

$$
U(p)= \begin{cases}\alpha-\beta(k m-p) & \text { if pays cash (C) } \\ \gamma \sqrt{p} & \text { non-cash payment (NC) and } k=1 \\ \delta & \text { non-cash payment (NC) and } k \geq 2\end{cases}
$$

The utility function (2) is depicted in Figure 1 assuming that $\alpha>\beta m>0, \alpha>\gamma \sqrt{m}$, and $\gamma>$ $[\alpha-\beta(m-\widehat{p})] / \sqrt{\widehat{p}}$ for some $\widehat{p} \in(0, m)$.

To derive the intuition behind the utility function (2) and Figure 1 it is easier to start with the case of $k \geq 2$ (larger payment amounts). In this case, the consumer chooses to pay cash if the first row in (2) is larger than the third row, formally, if $\alpha-\beta(k m-p) \geq \delta$. The third row is a fixed utility derived from a non-cash payment. The first row corresponds to the upward sloping straight lines in Figure 1, which show that utility of paying cash rises as the payment amount $p$ gets closer to an exact multiple of $\$ m$. This reflects consumer aversion to receiving and carrying change which diminishes as the price gets closer to $k m$. At price levels $p_{2}, p_{3}, \ldots p_{k}$, these lines cross $\delta$ so the utility from paying cash becomes larger than the utility of making a non-cash payment.

\footnotetext{
${ }^{2}$ It should be emphasized that the term utility refers to the net gain (benefit minus cost) consumers derive from the paying using a particular payment instrument. Here, the use of the term utility is substantially different from the common use of utility to measure the benefits derived from consuming a product or service.
} 
The case of $k=1$ is different as shown in Figure 1 for the range of payment amounts $p \in(0, m]$. This is formally captured by the second row in the utility function (2). This modification supports the observation that cash is heavily used for low-value payments (say, less than \$1) and also for higher payment values that are close to the currency denomination $\$ m$ such as $p=\$ 19.50$. In this case, $\alpha-\beta(k m-p)>\gamma \sqrt{p}$ for very low payment values in the range of $p \in\left[0, p_{0}\right]$ and also

for higher payment values close to the currency denomination $\$ m$ defined by $\left.p \in\left[p_{1}, m\right]\right]^{3}$ For intermediate payment values $p \in\left(p_{0}, p_{1}\right)$ this consumer prefers to pay with a non-cash payment instrument.

Finally, the model defined by the utility function (2) and visualized in Figure 1 is simple and therefore have limitations. First, the utility function (2) does not apply to all consumers. In fact, the data analyzed in the following sections reflect some variations across individuals. However, this type of preferences seems to capture perhaps the average behavior of consumers in situations when they have to decide whether to pay cash or with a non-cash payment instrument.

A second limitation of the model is that it applies only to a single-denomination currency note. To be more specific, the model does not capture an economy with more than one currency denomination. For example, in the US, consumers may carry $\$ 5, \$ 10$, and $\$ 20$ bills whereas the model captures only one of these denominations.

\section{Data, variable selection, and coding}

The study of consumer payment choice at the point-of-sale (POS) involves a classification of payment methods such as cash, paper checks, credit cards, debit cards, and prepaid cards. Data on "how consumers pay" are collected by consumer surveys in which consumers list all the payment instruments they have (adopt) and whether and how they use them at the POS. In particular, $d i$ ary surveys record, either in real time or by the end of each day, all consumers' payment-related activities including dollar amount, spending type, merchant type, and payment method, as well as money transfers in general and ATM cash withdrawals in particular.

\footnotetext{
${ }^{3}$ The length of the low-value payments interval $\left(0, p_{0}\right]$ could be smaller than the length of the interval $\left[p_{1}, m\right]$. Therefore, even if $m=\$ 100$, the length of the interval $\left(0, p_{0}\right]$ could still be $\$ 1$. This adjustment can be made by varying the value of the parameter $\gamma$ in the utility function (2). In fact, a more general utility function could also control the curvature by adding a parameter $\theta$, so the second row in (2) could be reformulated as $\gamma p^{\theta}$, where $0<\theta<1$.
} 
The data are taken from the 2017 and 2018 Diary of Consumer Payment Choice (DCPC). ${ }^{4}$ The DCPC is a representative sample of US consumers that records transactions during three consecutive days during the month of October. Transactions include purchases, bill payments, ATM withdrawals and deposits. Respondents' three-day diaries were evenly distributed throughout the months of October 2017 and October 2018 in a way that resembles a three-period overlapping generations model. ${ }^{5}$

The DCPC has a large number of variables describing all sorts of demographics and transactions. For the purpose of this article, I will focus only on a subset of variables, some of which I describe below. ${ }^{6}$ In particular, I restrict the analysis to 16,951 "in-person" (in-person $=1$ ) expenditure ("type" =1) payments made by 2891 unique respondents. Note that this restriction is needed because cash can only be paid in person as opposed to online or via the mail. Then, the sample was further restricted to 14,293 payments made by 2723 respondents who made purchases in seven merchant categories (merch $=1$ to 7 ) using the five major payment methods (pi $=1$ to 5): "cash," "check," "credit card," "debit card," and "prepaid card."7 This restriction is needed to ensure that all (or most) merchants accept all five payment methods, thereby avoiding merchant types that may not accept cash or credit cards. Other variables used include "amnt" (dollar amount of each payment), "age," "income_hh" (household income), "hh_size" (number of persons in the household), "work," "gender," and "education" (highest degree).

Finally, a note about the use of sampling weights. The data contain weights for all respondents that can be used to match the data with the US adult population (18 and older). I indicate when the reported statistics are computed with weights either by (weighted) or (w) inside tables. In

\footnotetext{
${ }^{4}$ The diary is conducted in collaboration of the Federal Reserve Banks of Atlanta, Boston, and San Francisco. The data and assisting documents (codebooks) are publicly available for downloading from the Federal Reserve Bank of Atlanta Website: https://www.frbatlanta.org/banking-and-payments/consumer-payments.aspx, and are summarized in Greene and Stavins (2018) and Kumar and O'Brien (2019). Similar surveys are conducted by the Bank of Canada, see Henry, Huynh, and Welte (2018).

${ }^{5}$ Jonker and Kosse (2009) compare payment diaries with different time lengths and find that shorter diaries yield more accurate information due to "survey fatigue" that leads respondents to underreport their payment activities.

${ }^{6}$ The data and the R-code used in this analysis are available for downloading from the author's Webpage: www. ozshy.com.

${ }^{7}$ The merchant categories (number of payments within the category) are: 1 . Grocery stores, convenience stores without gas stations, pharmacies (3718), 2. gas stations (2408), 3. sit-down restaurants and bars (1422), 4. fast food restaurants, coffee shops, cafeterias, food trucks (2963), 5. general merchandise stores, department stores, other stores (2761), 6. general services: hair dressers, auto repair, parking lots, laundry or dry cleaning, etc. (602), 7. Arts, entertainment, recreation (419).
} 
general, statistics on small subsamples or subgroups are reported without weights, because adequate demographic weighting is impossible without significantly increasing the variance of the estimators.

\section{Some statistics on ATM cash withdrawals}

Most ATMs in the United States dispense $\$ 20$ bills. Single-denomination ATMs are most common because they require less maintenance than ATMs that dispense multiple denominations. In particular, ATMs located outside bank branches, such as ATMs located at convenience stores, restaurants, and bars, are of smaller sizes which make them technically limited to single denomination. However, in the past 6 years, some large banks began introducing new ATMs that allow customers to withdraw bills of different denominations including $\$ 5$ and $\$ 10$ bills. $^{8}$

In 2017, 131 diary respondents made 141 ATM cash withdrawals during their three diary days. In 2018, 119 diary respondents made 129 ATM cash withdrawals during their three diary days. These include respondents who participated in both the 2017 and the 2018 diary surveys. From the combined sample of respondents who withdrew cash from ATMs, 13 withdrew twice and 3 withdrew cash three times or more during their 3 diary days.

Focusing on ATM cash withdrawal dollar amounts, $\$ 5$ was the lowest and $\$ 750$ was the highest amount. The median amount was $\$ 80$ and the mean was $\$ 115.6$. The top panel in Figure 2 displays the number of ATM withdrawals for each dollar amount ignoring one $\$ 540$, one $\$ 700$, and one $\$ 750$ ATM withdrawals. The bottom panel in Figure 2 is restricted to withdrawals not larger than $\$ 200$. Both panels show that $\$ 100$ was the most frequently withdrawn amount, followed by $\$ 40$, $\$ 20, \$ 200, \$ 60, \$ 80$, and $\$ 300$, in this order. All these amounts are multiples of $\$ 20$ which provide the key motivation for this research. More precisely, out of all ATM withdrawals in this sample, 89.26 percent are in multiples of $\$ 20$ whereas the remaining 10.74 percent are not in $\$ 20$ multiples. Note that the percentage of $\$ 20$ bills in ATM withdrawals is higher than 89.26 percent because, for example, consumers who withdraw $\$ 50$ from an ATM are most likely to get it as $2 \times \$ 20$ bills and one $\$ 10$ bill.

\footnotetext{
${ }^{8}$ See, https://money.cnn.com/2013/01/17/pf/atm-bills/index.html.
} 


\section{Empirical results}

This section utilizes visual and statistical techniques to evaluate the effect of the $\$ 5, \$ 10$, and $\$ 20$ currency denominations supplied by ATMs, on consumers' decision whether to pay cash. The goal is to estimate the threshold payment values above which there are significant drops in cash payments relative to non-cash payments.

Using the data described in Section 3, the vertical axis in Figure 3 displays the relative share of payments made with cash, checks, credit, debit, and prepaid cards. The horizontal axis measures actual payment dollar amounts in $\$ 1$ intervals (total 45 intervals). The unequal spacing on the horizontal (Amount) axis reflects the relative number of transactions made at each payment amount interval. Since the number of transactions declines very rapidly towards transaction values above $\$ 45$, this figure is restricted to payment amounts up to $\$ 45$ dollars.

Overall, Figure 3 verifies the common observation that the share of cash use declines with the payment amount. But, perhaps, the most striking observations in Figure 3 are the sharp drops in the share of cash use in payment amounts between $\$ 20$ and $\$ 21$ and between $\$ 40$ and $\$ 41$. Other somewhat smaller drops in cash use are also observed in transactions values between $\$ 5$ and $\$ 6$, $\$ 10$ and $\$ 11, \$ 15$ and $\$ 16, \$ 25$ and $\$ 26$, and $\$ 30$ and $\$ 31$.

\subsection{Asymmetric discontinuities in consumer payment choice}

The top panel in Figure 4 shows that the share of cash payments peaks at the following payment amount intervals: \$0-\$1 (87.9\%), \$4-\$5 (65.8\%), \$9-\$10 (54.1\%), \$14-\$15 (42.1\%), \$19-\$20 (53.6\%), \$24-\$25 (34.3\%), \$29-\$30 (26.9\%), and \$39-\$40 (42.5\%).

The middle panel in Figure 4 depicts the difference (increase/drop) in the share of cash payments associated with a $\$ 1$ increase in the payment amount. More precisely, the middle part in Figure 4 shows:

- $65.8 \%-59.4 \%=+6.4 \%$ increase between $\$ 4$ and $\$ 5$,

- $56.6 \%-65.8 \%=-9.2 \%$ drop between $\$ 5$ and $\$ 6$;

- $54.1 \%-41.6 \%=+12.4 \%$ increase between $\$ 9$ and $\$ 10$,

- $37.6 \%-54.1 \%=-16.5 \%$ drop between $\$ 10$ and $\$ 11$; 
- $42.1 \%-25.4 \%=+16.6 \%$ increase between $\$ 14$ and $\$ 15$,

- $30.8 \%-42.1 \%=-11.2 \%$ drop between $\$ 15$ and $\$ 16$;

- $53.6 \%-24.3 \%=+29.2 \%$ increase between $\$ 19$ and $\$ 20$,

- $26.1 \%-53.6 \%=-27.4 \%$ drop between $\$ 20$ and $\$ 21$;

- $34.3 \%-20.3 \%=+13.9 \%$ increase between $\$ 24$ and $\$ 25$,

- $20.3 \%-34.3 \%=-14.0 \%$ drop between $\$ 25$ and $\$ 26$;

- $26.9 \%-20.4 \%=+6.5 \%$ increase between $\$ 29$ and $\$ 30$,

- $12.0 \%-26.9 \%=-14.8 \%$ drop between $\$ 30$ and $\$ 31$;

- $42.5 \%-12.0 \%=+30.5 \%$ increase between $\$ 39$ and $\$ 40$,

- $8.4 \%-42.5 \%=-34.1 \%$ drop between $\$ 40$ and $\$ 41$.

The above list shows that the sharpest drops in cash use is in payment amounts between $\$ 20$ and $\$ 21(-27.4 \%)$ and between $\$ 40$ and $\$ 41(-34.1 \%)$. Both, the sharp increase in share of cash use and the sharp drop in cash use around the $\$ 20$ and the $\$ 40$ payment amounts make it clear that a large number of consumers use multiples of $\$ 20$ payment amounts as thresholds above which they switch from paying cash to paying with cards.

The above list demonstrates an asymmetric behavior just below and just above each payment amount threshold. For example, the use of cash increases by 29.2 percent for payment amounts just below the $\$ 20$ and drops by 27.4 percent for payment amounts just above $\$ 20$. This behavior is also predicted by the theoretical model, see Figure 1. What can explain such an asymmetric change in consumers' cost or benefit from paying cash?

One explanation for this asymmetry is that consumers, who carry only multiples of $\$ 20$ currency notes, prefer to minimize the total dollar value of change they received from each payment. For example, any payment amount in the range of $\$ 39$ to $\$ 40$ would leave the payer with change between $\$ 0$ to $\$ 1$. In contrast, any payment amount in the range of $\$ 40$ to $\$ 41$ would leave the payer with change between $\$ 19$ to $\$ 20$, assuming that the consumer pays with three $\$ 20$ bills $(3 \times \$ 20)$, and hence receives change from $\$ 60$.

Intuitively, the above explanation may imply that consumers prefer not to break an additional $\$ 20$ bill for transaction amounts just above multiples of $\$ 20$, such as: $\$ 20.50, \$ 40.50, \$ 60.50$, and 
so on. Exactly the same explanation holds for the multiples of $\$ 10$ and $\$ 5$ threshold payment amounts. For example, consumers who have some $\$ 5$ bills in their pocket, may still hesitate breaking another $\$ 5$ bill for payment amounts such as $\$ 5.20, \$ 15.25, \$ 25.75$, and so on.

Another related explanation is that consumers try to minimize computation or thinking time involved with each payment. To make a $\$ 19.50$ payment, the consumer can simply hand in one $\$ 20$ bill without much thinking, and get back 50ф change. However, paying \$20.50 will require the consumer to check what types of coin or low- denomination bills the consumer has, which is more time consuming.

The following three subsections test this hypothesis using three statistical methods: (5.2) machine learning classification tree, (5.3) logistic regression, and (5.4) de-trending with respect to payment dollar amounts. These three statistical techniques rely on totally different complementary methods for the investigation of correlation between ATM and currency denominations and the decision to pay cash. Relying on these diverse methods increases the researcher's confidence that the established correlations reflect actual consumer behavior.

\subsection{Payment method classification tree}

In the context of machine learning, a classification tree displays an optimized algorithm in the form of an upside-down tree. The tree illustrates how the machine (software) splits and classifies the payment methods with the objective of minimizing a function of the number of classification errors among the predicted payment methods relative to the actually-used methods. ${ }^{9}$

Figure 5 displays an upside-down tree that classifies the use of the payment methods (cash, checks credit, debit, and prepaid cards) according to payment amount and payers' demographic features that were described in Section 3. For the sake of illustration, the classification tree displayed in Figure 5 was pruned by setting the complexity parameter to generate only 8 splits. The tree was constructed using the restricted sample with 14,043 in-person payments made by 2705

\footnotetext{
${ }^{9}$ The classification tree algorithm is constructed and tuned with cross validation using the rpart R-package and plotted using the partykit R-package. The cross validation procedure partitions the data into $k$ folds, where the algorithm is constructed using $k-1$ folds of data and tested on the retained $k$ 's fold on which the classification errors are measured. The process repeats itself $k$ times, each with a different retained $k$ 's fold. The $k$ error measurements are then averaged to produce the final tree algorithm. The advantage of this method is that all observations are used for both training and validation.
} 
respondents at the merchant types described in Footnote 7 using five payment methods: cash, checks, credit, debit, and prepaid cards. Because of their low use in the sample, check and prepaid card payments are not predicted by this tree.

Figure 5 shows that the $\$ 10$ and $\$ 20$ payment amounts and the $\$ 109,835$ household income thresholds constitute the best three predictors for cash payments. The resulting cutoff dollar amounts have some unrealistic decimal points (such as \$10.005) because currency denominations are discrete numbers (with $1 \not$ increments in the US) which prevent the algorithm from splitting at the exact $\$ 10$ and $\$ 20$ amounts. The tree algorithm selects these splits to be on the top because these thresholds reduce classification errors more than top splits according to age (that are pushed to lower branches of the tree). The exact top splitting amount ( $\$ 10$ in this sample) is determined by the error "majority rule" (or some function of it) in the sense that any other split would generate lower prediction accuracy as measured by a function of the number of prediction errors.

The $\$ 10$ split on the top seems to capture low-value transactions especially transactions below $\$ 7$ that are dominated by cash, see Figure 3. The $\$ 10$ currency denomination has some effect that prevents the tree from splitting at payment values below $\$ 10$. The top-left branch shows that 5119 payments were classified as cash using this threshold. The 40.2 percent classification errors are consistent with Figure 3 which shows that about 60 percent of all payments up to $\$ 10$ were made with cash.

The second layer of branches in Figure 5 consists of splits according to a very high household income because high income levels predict high use of credit cards. The third layer splits according to the $\$ 20$ currency denomination threshold. The branch on the very left shows that 283 payments were exactly \$20 and were classified as cash (with only 31.4 error rate). On the right branch, transactions over $\$ 20$ were classified as either debit or credit depending on age and household income.

\subsection{Logistic regression discontinuity design}

Using the transaction data described in Section 3, define a binary variable "Cash" to take the value of 1 for cash payments and 0 for non-cash payments. Using 25 payment amount thresholds, the 
estimated model takes the form of

$$
\begin{aligned}
& \operatorname{Cash}_{i}=\sum_{k=1}^{25} \delta_{k} I\left\{\text { Amount }_{i}>k\right\}+\beta_{T} \text { Amount }_{i}+\beta_{W} \text { Work }_{i}+\beta_{S} \text { HH_size }_{i} \\
& +\beta_{I} \mathrm{HH} \text { income }_{i}+\beta_{M} \operatorname{Marital}_{i}+\beta_{A} \text { Age }_{i}+\beta_{G} \text { Gender }_{i}+\beta_{E} \text { Educ }_{i}+\epsilon_{i} .
\end{aligned}
$$

For each $k=1, \ldots, 25$ reflecting a $\$ 1$ increment in dollar amount, $I$ is the indicator function which takes a value $I=1$ if the payment amount is strictly greater than $k$ and $I=0$ otherwise, where $\delta_{k}$ is the corresponding coefficient to be estimated. ${ }^{10}$ The $\beta$ coefficients correspond to dollar amount and some of the demographic variables described in Section 3. The index $i$ corresponds to a single payment observation, $i=1,2, \ldots, 14,043$, made by 2705 respondents. Note that payments made by the same respondent have the same demographic values.

Table 1 and Figure 6 display the estimated marginal effects and their confidence intervals. Both show that the largest drop in cash use occurs at the $\$ 20$ threshold where the probability of paying cash drops by 32.2 percent. An equally striking result is the sharp increase in the probability of paying cash between $\$ 19$ and $\$ 20$. That is, the probability of paying cash increases by 27 percent for payment amounts between $\$ 19$ to $\$ 20$ (inclusive).

The marginal effects at other thresholds are substantially lower. The probability of cash use drops by 17.2 percent between $\$ 1$ and $\$ 2$ payment values and by 16.6 percent between $\$ 2$ and $\$ 3$ which may reflect a switch from coin transactions to more currency note transactions. There is a 17 percent drop in the probability of cash use between $\$ 10$ and $\$ 11$, however, unlike the $\$ 19$ to $\$ 20$ threshold, the increase between $\$ 9$ and $\$ 10$ is only 9.4 percent. There is a 18.4 percent drop in the probability of cash use between payment amounts $\$ 25$ and $\$ 26$.

Finally, looking at the demographic marginal effects in Table 1, the probability of using cash declines with education and slightly increases with age.

\footnotetext{
${ }^{10}$ The $\delta_{k}$ are linearly independent because $I$ \{ Amount $\left._{i}>k-1\right\}=1$ whereas $I\left\{\right.$ Amount $\left._{i}>k\right\}=0$ for any Amount $_{i} \in(k-1, k]$. A similar model was estimated in Chen, Huynh, and Shy (2019) using Bank of Canada's 2013 Methods of Payment diary data.
} 


\subsection{De-trending according to payment amount}

To further test the hypothesis that the $\$ 20$ currency denomination (and perhaps other multiples of \$5) have significant impacts on consumer payment choice, this subsection takes a different approach by separating the negative relationship between the share of cash use and payment amount from the local jumps and drops around the threshold payment amounts. More precisely, recall from Figure 3 and the top panel in Figure 4 that the share of cash use declines with the dollar amount. To separate this downward trend from the local jumps and drops, the analysis in this subsection 'de-trends' the share of cash use with respect to payment dollar amount.

The bottom panel in Figure 4 depicts the share of cash use for each payment amount after it is subtracted from the regression line depicted on the top panel in Figure 4. This procedure 'de-trends' the negative effect of dollar amount on the share of cash use and shows the jumps and drops in cash use relative to the trend in shares of cash use. The bottom panel shows that the highest de-trended share of cash use is at payment values between $\$ 19$ and $\$ 20$ followed by $\$ 39$ to $\$ 40$, and then $\$ 0$ to $\$ 1$. These findings provide additional support for the hypothesis that consumer choice of paying cash is influenced by payment dollar amounts closer to multiples of $\$ 20$ bills. Multiples of $\$ 5$ payment amounts also exhibit high shares of cash payments although lower than multiples of $\$ 20$.

\section{Conclusion}

This article identifies significant discontinuities in consumer payment choice between payment amounts $\$ 19$ and $\$ 21$ and also between $\$ 39$ and \$41. It also identifies discontinuities in payment amounts that are multiples of $\$ 5$. Whereas this research establishes a correlation between ATM and currency denomination with consumer payment choice, the exact cause of this behavior cannot be derived. However, this behavior may reflect consumer aversion to receiving and carrying change. The asymmetry in behavior around the threshold payment amounts reflects higher aversion for receiving large value of change, and also aversion to having to "break" an additional large denomination currency note. A serious limitation of this type of research is the lack of data on the exact coin and currency denominations respondents have in their wallet or pocket before each 
payment is made.

The empirical findings described in this paper reveal discontinuities not only at the $\$ 20$ payment threshold, but also at payment amounts that are multiples of $\$ 5$, such as $\$ 5, \$ 10, \$ 10+\$ 5$, $\$ 20, \$ 20+\$ 5$, and so on. These findings may indicate that ATM currency denomination plays only a secondary role relative to the role of all issued currency denominations of the US dollar. That may be indeed the case. As pointed out in the introduction, some major banks started installing ATMs that provide $\$ 10$ bills and some even $\$ 5$ bills. Moreover, some people get cash directly from their employers and some directly from customers (although customers may also get their cash from ATMs). Some consumers also get cash from bank tellers, who can provide all available denominations.

One way of testing whether ATM currency denominations play a role in explaining the observed consumer behavior is to provide a representative sample of US consumers access to ATMs that dispense all available currency denominations, including $\$ 1$ bills. Then, if the payment thresholds identified in this paper remain significant, that would indicate that ATM currency denominations do not play a significant role in explaining these thresholds. In the other extreme, if these threshold become insignificant, then ATMs do play a role in explaining this behavior. Clearly, such an experiment is extremely costly and is unlikely to be conducted.

This research has also some policy implications for how optimal currency could be designed to minimize the burden of change. In fact, in the literature, there have been several attempts to compute the optimal currency denominations according to the "principle of least effort," as discussed in Telser (1995), Van Hove (2001), and Shallit (2003) for the case of optimal coin denomination. Other literature on optimal denominations includes Cramer (1983), Van Hove and Heyndels (1996), Wynne (1997), Tschoegl (1997), Sargent and Velde (1999, 2003), and Lee, Wallace, and Zhu (2005).

However, this literature does not take into consideration that even if central banks issue the effort-minimizing currency denominations, consumers may not be able to obtain all available currency denominations if most ATMs provide only one type of currency ( $\$ 20$ bills in the United States). Part of this distortion may be captured in the analysis of this paper. 


\section{References}

Arango, Carlos, Kim Huynh, and Leonard Sabetti. 2015. "Consumer Payment Choice: Merchant Card Acceptance Versus Pricing Incentives." Journal of Banking and Finance 55:130-141.

Bagnall, John, David Bounie, Kim Huynh, Anneke Kosse, Tobias Schmidt, Scott Schuh, and Helmut Stix. 2016. "Consumer Cash Usage: A Cross-Country Comparison with Payment Diary Survey Data." International Journal of Central Banking 12 (4):1-61.

Bech, Morten, Umar Faruqui, Frederik Ougaard, and Cristina Picillo. 2018. "Payments are achangin' But Cash Still Rules." BIS Quarterly Review, March.

Bouhdaoui, Yassine, David Bounie, and Abel François. 2014. "Convenient Prices, Cash Payments and Price Rigidity." Economic Modelling 41:329-337.

Bounie, David, Abel François, and Patrick Waelbroeck. 2016. "Debit Card and Demand for Cash." Journal of Banking and Finance 73:55-66.

Chen, Heng, Kim Huynh, and Oz Shy. 2019. "Cash Versus Card: Payment Discontinuities and the Burden of Holding Coins." Journal of Banking and Finance 99:192-201.

Cramer, Jan Salomon. 1983. “Currency by Denomination.” Economics Letters 12 (3-4):299-303.

Fung, Ben, Kim Huynh, and Gerald Stuber. 2015. "The Use of Cash in Canada." Bank of Canada Review 2015 (Spring):45-56.

Greene, Claire and Joanna Stavins. 2018. “The 2017 Diary of Consumer Payment Choice.” Federal Reserve Bank of Atlanta, Research Data Report No. 2018-5.

Henry, Christopher, Kim Huynh, and Angelika Welte. 2018. “2017 Methods-of-Payment Survey Report." Bank of Canada Staff Discussion Paper 2018-17.

Jonker, Nicole and Anneke Kosse. 2009. "The Impact of Survey Design on Research Outcomes: A Case Study of Seven Pilots Measuring Cash Usage in the Netherlands." De Nederlandsche Bank Working Paper No. 221/2009.

Khiaonarong, Tanai and David Humphrey. 2019. "Cash Use Across Countries and the Demand for Central Bank Digital Currency." IMF Working Paper No. 19/46.

Knotek, Edward. 2008. "Convenient Prices, Currency, and Nominal Rigidity: Theory with Evidence From Newspaper Prices." Journal of Monetary Economics 55 (7):1303-1316.

- 2011. "Convenient Prices and Price Rigidity: Cross-Sectional Evidence." Review of Economics and Statistics 93 (3):1076-1086. 
Krüger, Malte and Franz Seitz. 2014. "Costs and Benefits of Cash and Cashless Payment Instruments: Overview and Initial Estimates." Study commissioned by the Deutsche Bundesbank.

Kumar, Raynil and Shaun O’Brien. 2019. “2019 Findings from the Diary of Consumer Payment Choice." Federal Reserve Bank of San Francisco.

Lee, Manjong, Neil Wallace, and Tao Zhu. 2005. "Modeling Denomination Structures." Econometrica 73 (3):949-960.

Levy, Daniel and Andrew Young. 2004. "The Real Thing: Nominal Price Rigidity of the Nickel Coke, 1886-1959." Journal of Money, Credit and Banking 36 (4):765-799.

Sargent, Thomas and François Velde. 1999. "The Big Problem of Small Change." Journal of Money, Credit, and Banking 31 (2):137-161.

- 2003. The Big Problem of Small Change. Princeton University Press.

Shallit, Jeffrey. 2003. "What This Country Needs is an 18 $\not$ Piece." The Mathematical Intelligencer 25 (2):20-23.

Shy, Oz. 2018. "Alternative Methods for Studying Consumer Payment Choice." Available at SSRN No. 3176715.

_ 2019. "Cashless Stores and Cash Users." Federal Reserve Bank of Atlanta, Working Paper No. 2019-11.

Telser, Lester. 1995. “Optimal Denominations for Coins and Currency." Economics Letters 49 (4):425-427.

Tschoegl, Adrian. 1997. "The Optimal Denomination of Currency." Journal of Money, Credit and Banking 29 (4):546-554.

Van Hove, Leo. 2001. “Optimal Denominations for Coins and Bank Notes: In Defense of the Principle of Least Effort." Journal of Money, Credit and Banking 33 (4):1015-1021.

Van Hove, Leo and Bruno Heyndels. 1996. "On the Optimal Spacing of Currency Denominations." European Journal of Operational Research 90 (3):547-552.

Wakamori, Naoki and Angelika Welte. 2017. "Why Do Shoppers Use Cash? Evidence from Shopping Diary Data." Journal of Money, Credit and Banking 49 (1):115-169.

Wang, Zhu and Alexander Wolman. 2016. "Payment Choice and Currency Use: Insights from Two Billion Retail Transactions." Journal of Monetary Economics 84 (C):94-115.

Wynne, Mark. 1997. “More on Optimal Denominations for Coins and Currency." Economics Letters 55 (2):221-225. 


\begin{tabular}{rrrlrr}
\hline Amount Threshold & $\delta_{k}, \beta$ & Std.Err. & Sig. & \multicolumn{2}{r}{ Conf. Interval } \\
\hline Amount $>\$ 1$ & -0.172 & 0.074 & $*$ & -0.318 & -0.026 \\
Amount $>\$ 2$ & -0.166 & 0.050 & $* * *$ & -0.265 & -0.067 \\
Amount $>\$ 3$ & -0.078 & 0.046 & & -0.168 & 0.013 \\
Amount $>\$ 4$ & 0.082 & 0.036 & $*$ & 0.011 & 0.153 \\
Amount $>\$ 5$ & -0.070 & 0.041 &. & -0.150 & 0.010 \\
Amount $>\$ 6$ & -0.058 & 0.043 & & -0.141 & 0.025 \\
Amount $>\$ 7$ & -0.101 & 0.047 & $*$ & -0.193 & -0.008 \\
Amount $>\$ 8$ & 0.028 & 0.048 & & -0.065 & 0.122 \\
Amount $>\$ 9$ & 0.094 & 0.041 & $*$ & 0.013 & 0.175 \\
Amount $>\$ 10$ & -0.170 & 0.045 & $* * *$ & -0.257 & -0.082 \\
Amount $>\$ 11$ & 0.017 & 0.051 & & -0.083 & 0.117 \\
Amount $>\$ 12$ & -0.036 & 0.054 & & -0.142 & 0.070 \\
Amount $>\$ 13$ & -0.089 & 0.062 & & -0.211 & 0.032 \\
Amount $>\$ 14$ & 0.069 & 0.061 & & -0.050 & 0.188 \\
Amount $>\$ 15$ & 0.004 & 0.060 & & -0.113 & 0.121 \\
Amount $>\$ 16$ & 0.059 & 0.065 & & -0.068 & 0.187 \\
Amount $>\$ 17$ & -0.160 & 0.066 & $*$ & -0.289 & -0.032 \\
Amount $>\$ 18$ & 0.024 & 0.076 & & -0.126 & 0.173 \\
Amount $>\$ 19$ & 0.270 & 0.064 & $* * *$ & 0.146 & 0.395 \\
Amount $>\$ 20$ & -0.322 & 0.058 & $* * *$ & -0.435 & -0.209 \\
Amount $>\$ 21$ & 0.037 & 0.082 & & -0.123 & 0.198 \\
Amount $>\$ 22$ & 0.064 & 0.077 & & -0.087 & 0.214 \\
Amount $>\$ 23$ & -0.079 & 0.079 & & -0.233 & 0.075 \\
Amount $>\$ 24$ & 0.116 & 0.077 & & -0.035 & 0.268 \\
Amount $>\$ 25$ & -0.184 & 0.041 & $* * *$ & -0.265 & -0.104 \\
Amount & -0.000 & 0.000 & $*$ & -0.001 & 0.000 \\
Not employed & -0.013 & 0.016 & & -0.043 & 0.018 \\
Household size & -0.004 & 0.006 & & -0.015 & 0.008 \\
Household income & -0.000 & 0.000 & $* * *$ & -0.000 & -0.000 \\
Age & 0.005 & 0.001 & $* * *$ & 0.004 & 0.006 \\
Male & -0.011 & 0.014 & & -0.037 & 0.016 \\
MA or higher & -0.226 & 0.032 & $* * *$ & -0.289 & -0.163 \\
\hline Associate or college & -0.220 & 0.035 & $* * *$ & -0.288 & -0.153 \\
\hline & & & & &
\end{tabular}

Table 1: Cash use logistic regression marginal effects.

Source: Author's calculations from the 2017 and 2018 diary of consumer payment choice.

Notes: (a) $\left({ }^{* *}\right),(* *),(*)$, and $(\cdot)$ correspond to the $99.9,99,95$, and 90 percent confidence levels, respectively. (b) The sample contains 14,043 payment observations by 2705 respondents. (c) The bottom three education variables are highest degrees. 


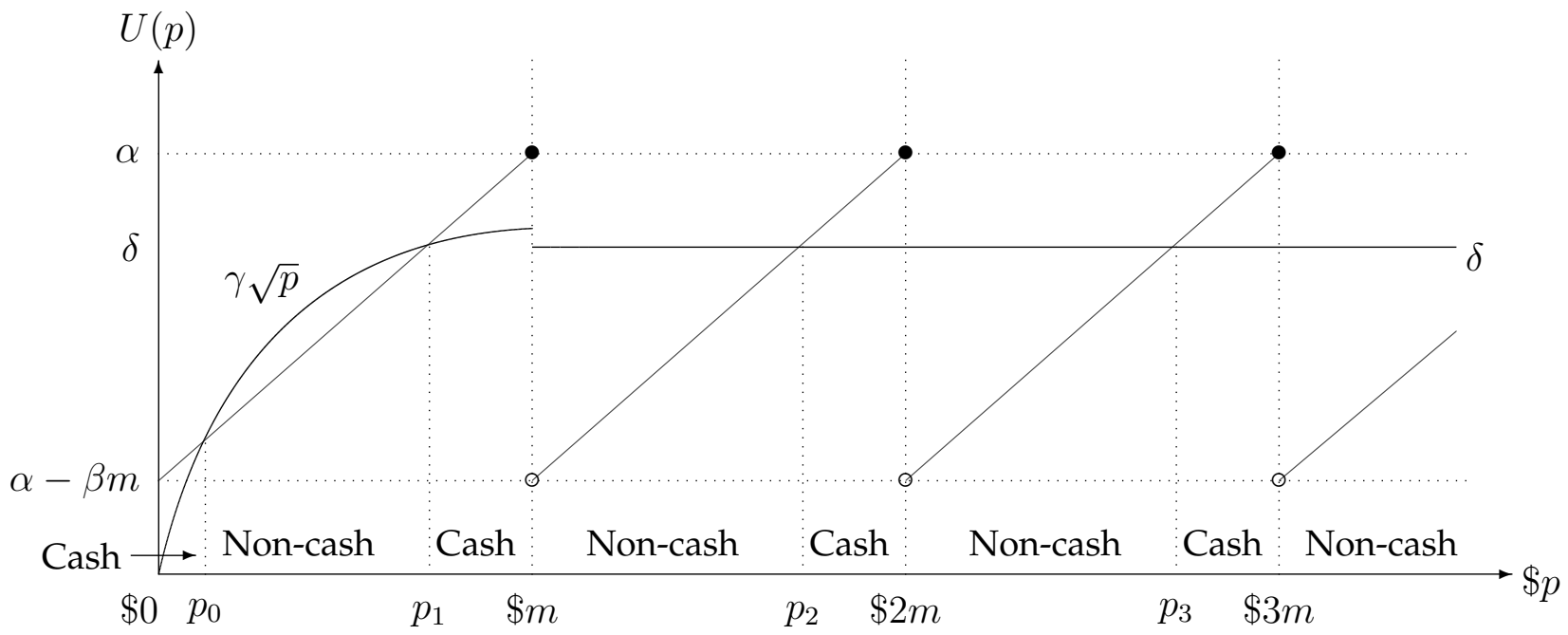

Figure 1: Utility (net benefit) from paying cash or with a non-cash payment instrument as functions of the payment dollar amount $p$.

Note: The figure assumes that buyers carry only multiples of $\$ \mathrm{~m}$ bills (for example, $\$ 20$ currency notes), and that buyers have no other forms of cash. 

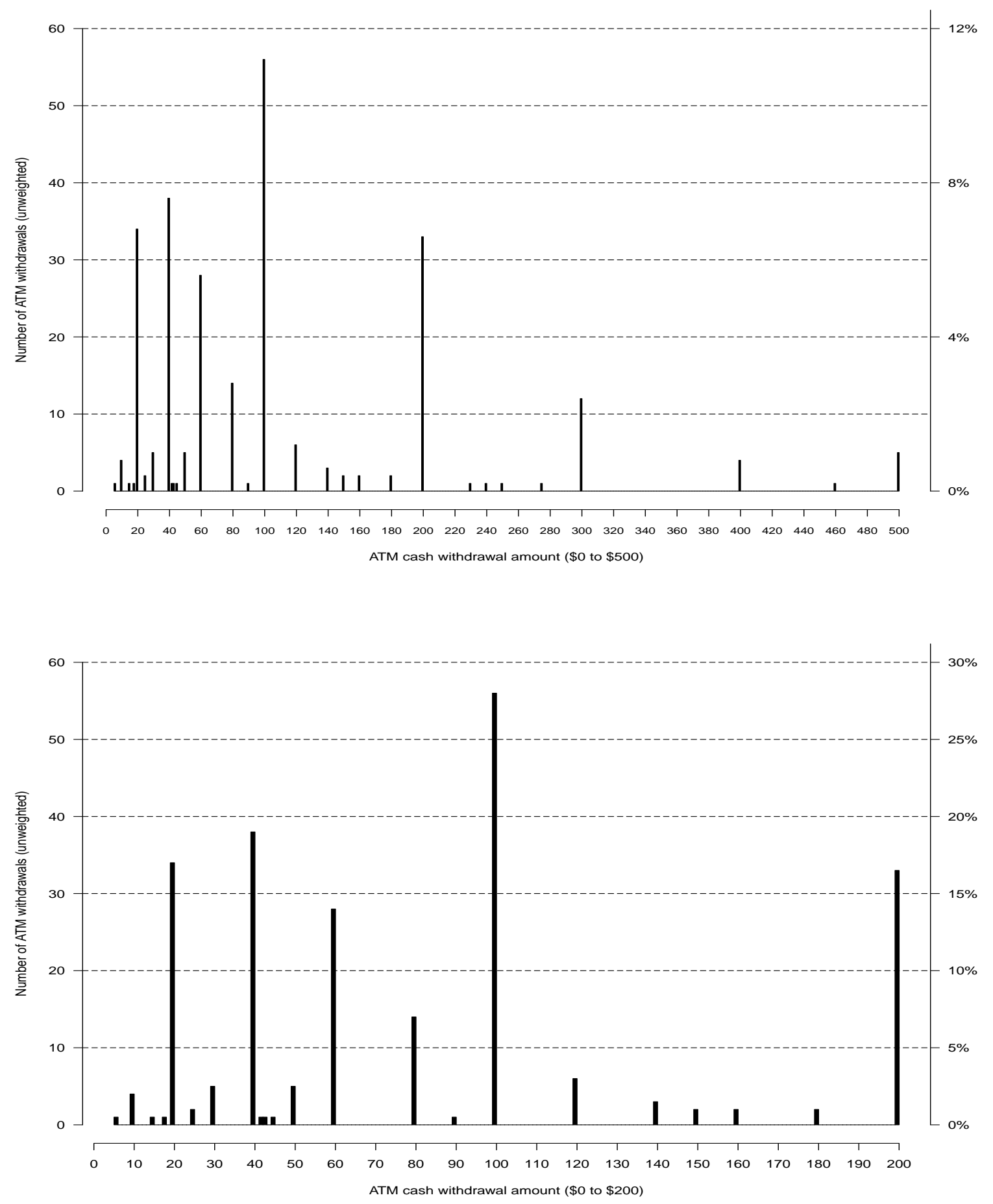

Figure 2: Number of ATM cash withdrawals by dollar amount.

Source: Author's calculations from the 2017 and 2018 diary of consumer payment choice.

Top: Withdrawals not exceeding \$500. Bottom: Withdrawals not exceeding \$200. 


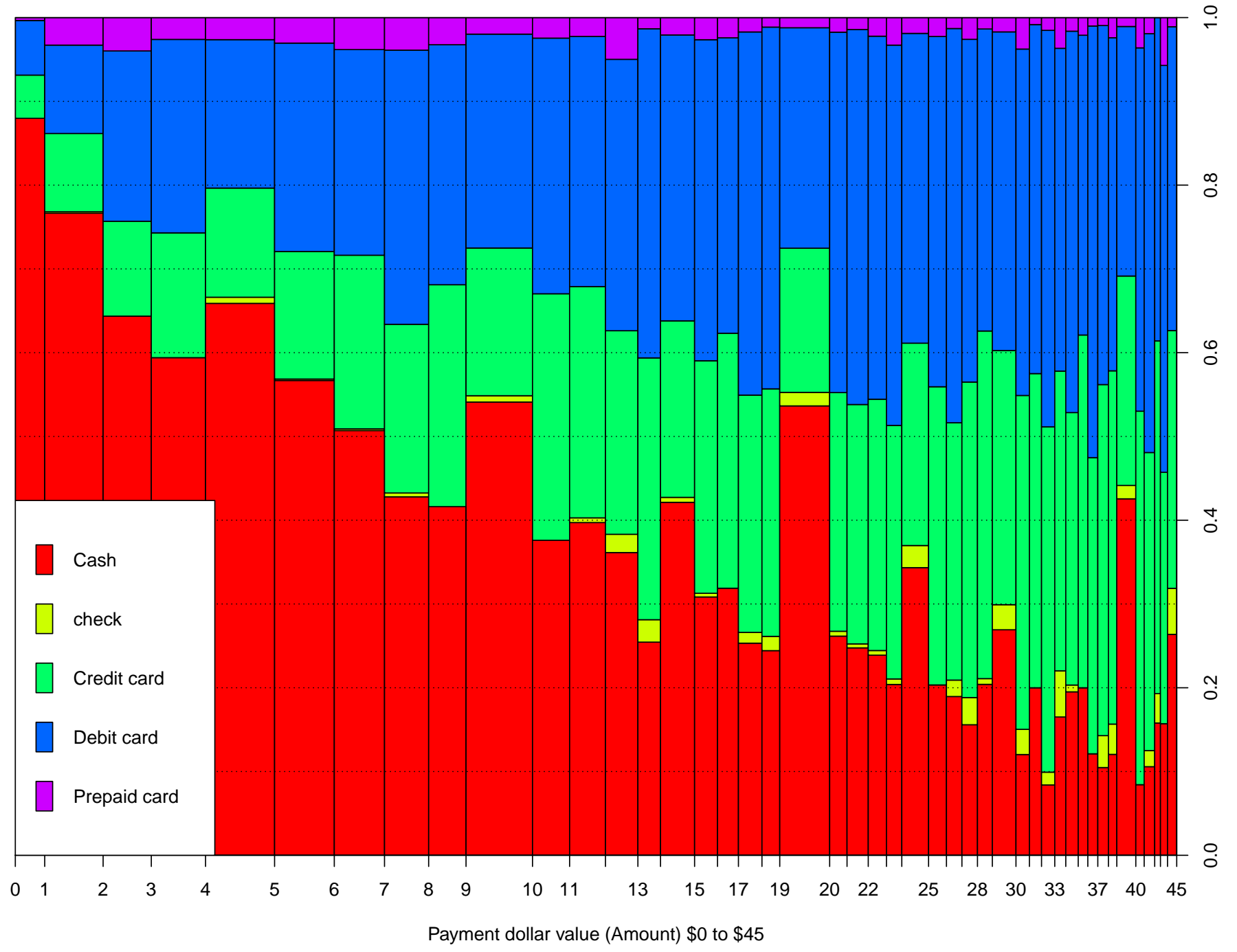

Figure 3: Share of use of cash, check, credit, debit, and prepaid card payments.

Source: Author's calculations from the 2017 and 2018 diary of consumer payment choice.

Notes: (a) The chart is based on 2573 respondents who made in-person 11,495 payments between $\$ 0$ to $\$ 45$. (b) Unequal spacing between each $\$ 1$ increment reflects relative number of payments at this dollar amount interval. 

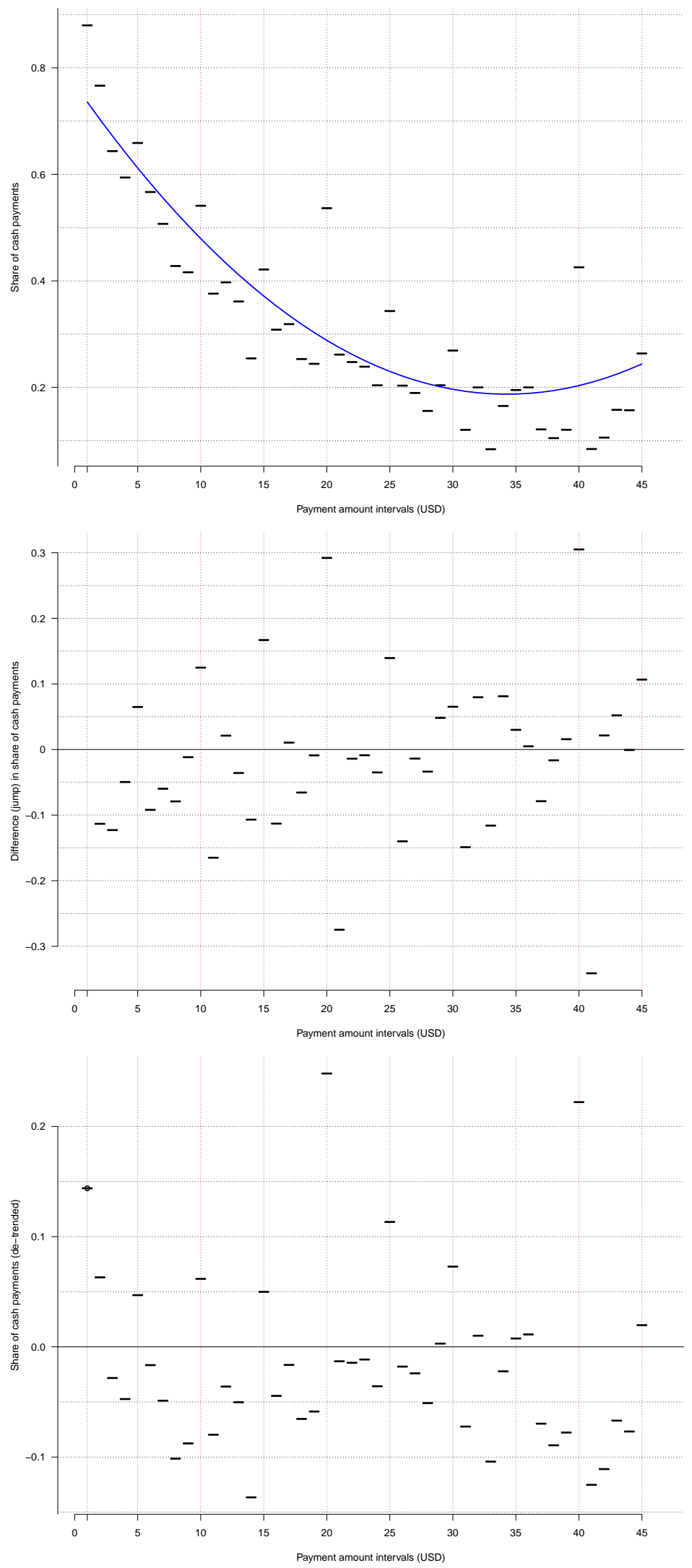

Figure 4: Share of use of cash by dollar amount

Source: Author's calculations from the 2017 and 2018 diary of consumer payment choice.

Note: Top: Shares of cash use by 2573 respondents who made 11,495 payments between $\$ 0$ and $\$ 45$ and regression curve. Middle: Differences (jumps and 211ops) in share of cash use between two consecutive payment amounts. Bottom: Share of cash use de-trended around the regression curve. 


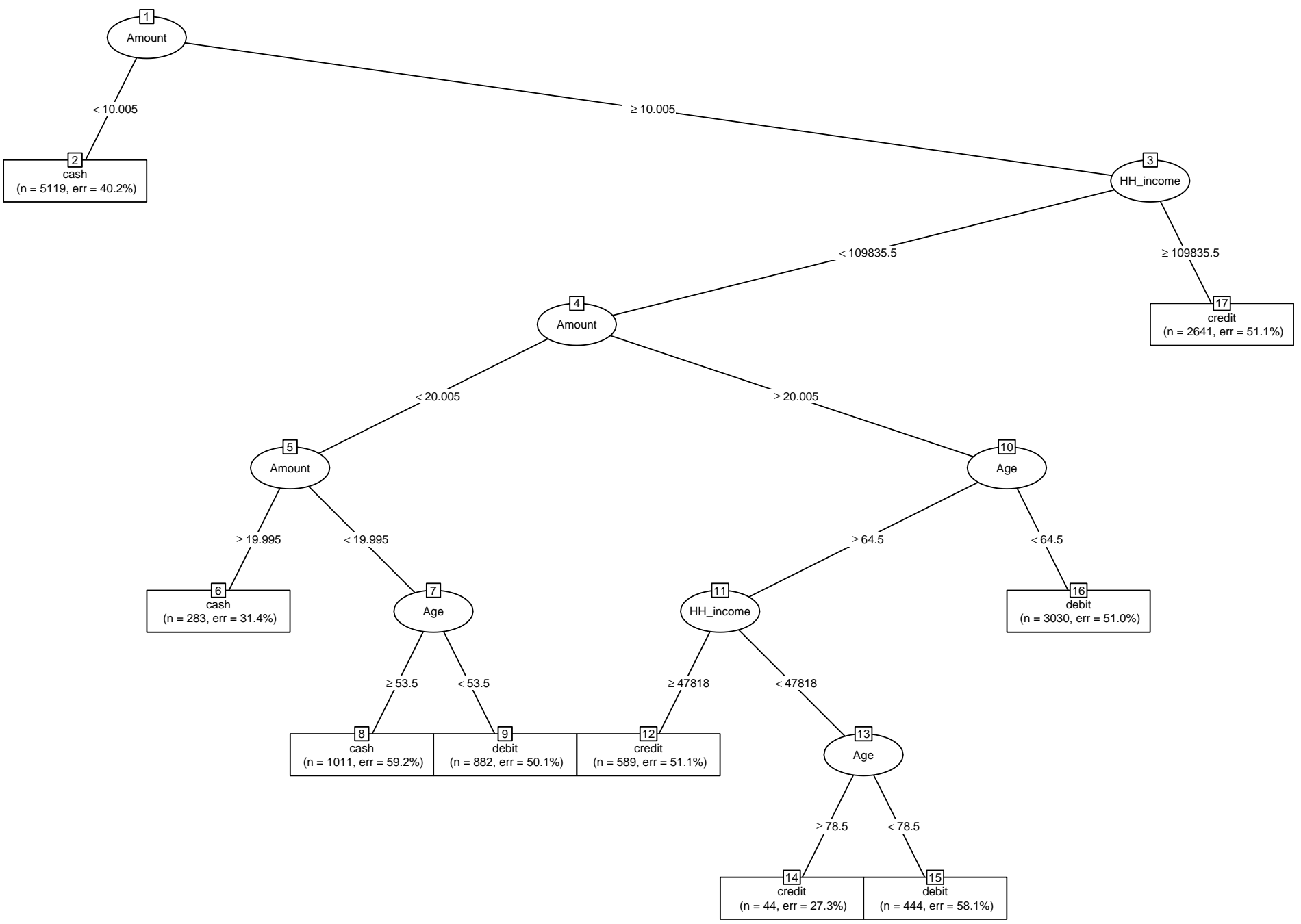

Figure 5: Payment method machine learning classification tree.

Source: Author's calculations from the 2017 and 2018 diary of consumer payment choice.

Notes: (a) The tree is based on 14,043 payment observations made by 2705 respondents. (b) Because of their low use, check and prepaid card payments are not predicted by this tree. 


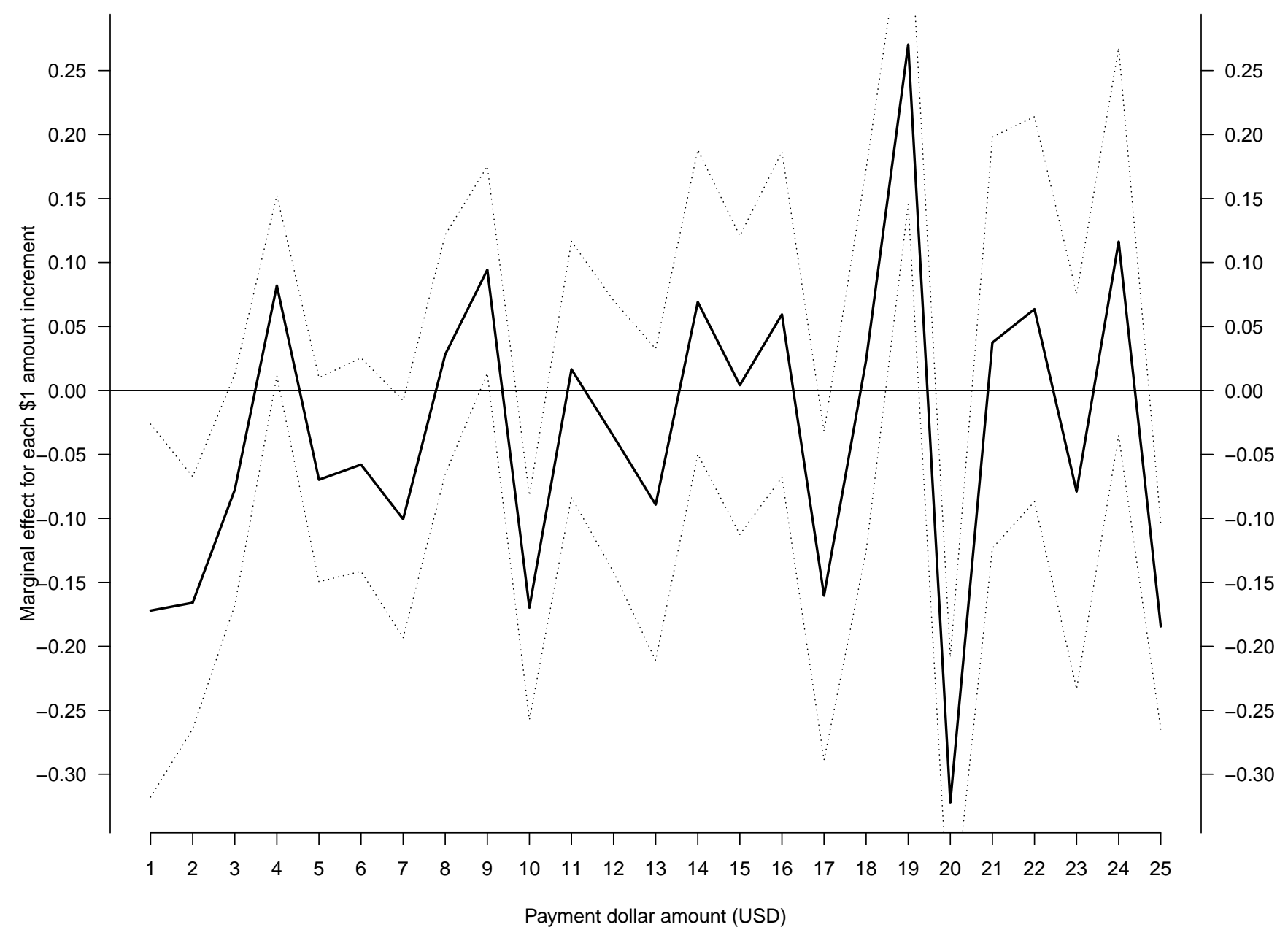

Figure 6: Marginal effects and 95-percent confidence intervals at each payment amount threshold.

Source: Author's calculations from the 2017 and 2018 diary of consumer payment choice. 